\title{
GRITO DE SOCORRO: TENHO MEDO DE MORRER - A VIOLÊNCIA DOMÉSTICA E O USO DA MEDIDA PROTETIVA
}

\section{CRY OF HELP: I FEAR TO DIE - DOMESTIC VIOLENCE AND THE USE OF PROTECTIVE MEASURE}

Elizangêla Silva Paiva ${ }^{1}$ Maisa França Teixeira²

Resumo: O presente artigo trata-se da Lei 11.340/06, mais conhecida como Lei Maria da Penha. Temse o objetivo de demonstrar a importância da lei citada. Para a realização de tal estudo, foram analisadas obras bibliográficas. Apresentando conceitos trazidos por Dias (2007), Mirabetti (2000), Souza (2009), entre outros; busca-se desenvolver o entendimento sobre as formas de violência dos casos onde a referida lei poderá ser aplicada. Seguindo esta linha de raciocínio, apresentam-se as soluções sustentadas pela lei Maria da Penha, analisando-se o contexto do caso concreto para aplicar-se uma medida eficaz. Ao estudarem-se estas medidas, nota-se a existência de vários casos aos quais não se verifica a eficácia da sansão imposta; neste diapasão, tem-se um breve estudo apresentando as principais causas que podem justificar a origem desta questão.

Palavras-chave: Agressão. Dignidade da pessoa humana. Eficácia da medida protetiva. Formas de Violência. Maria da Penha. Medida protetiva. Violência contra a mulher.

\begin{abstract}
This article deals with Law 11.340 / 06, better known as Lei da Maria da Penha. The objective is to demonstrate the importance of the aforementioned law. For the accomplishment of such a study, bibliographical works were analyzed. Presenting concepts brought by Dias (2007), Mirabetti (2000), Souza (2009), among others; It seeks to develop an understanding of the forms of violence in the cases where the said law may be applied. Following this line of reasoning, we present the solutions supported by the Maria da Penha law, analyzing the context of the concrete case to apply an effective measure. When studying these measures, we can notice the existence of several cases to which the effectiveness of the imposed Samson is not verified; In this tuning fork, we have a brief study presenting the main causes that can justify the origin of this question.
\end{abstract}

Keywords: Aggression. Dignity of human person. Efficacy of the protective measure. Forms of Violence. Maria da penha. Protective measure. Violence against women

\section{INTRODUÇÃO:}

A Lei 11.340/06, mais conhecida como Lei Maria da Penha, surgiu com o propósito de proteger as mulheres vítimas de seus agressores, visando propiciar a toda mulher, independente de classe social, cor, religião, raça, etnia entre outros uma vida com sua integridade moral, física e psicológica, sendo resguardados e assegurados todos os seus direitos.

É comum vermos nos noticiários o aumento desse tipo de agressão, onde mulheres são reprimidas e intimidadas por seus companheiros, chegam a negar a agressão por medo e até mesmo por dependência econômica e emocional.

Infelizmente por considerarem a mulher como sexo frágil, é vitimada a viver relações conturbadoras onde são desprezadas, agredidas fisicamente e verbalmente, levando-as a tristezas profundas com sentimentos de abandonos e até mesmo de culpa por não conseguirem reagir diante da realidade vivenciada por elas, afetando sua relação social entre outros.

${ }^{1}$ Graduada em Direito pela Faculdade Evangélica de Goianésia (FACEG).

${ }^{2}$ Graduação em Geografia pela Universidade Federal de Ouro Preto (UFOP). Mestrado em Geografia pela Universidade Federal de Goiás (UFG) e Doutora em Geografia pela Universidade Federal do Paraná (UFPR). Professora Adjunta no Departamento do Direito da Faculdade Evangélica de Goianésia (FACEG). 
No dia que for possível à mulher amar em sua força e não em sua fraqueza, não para fugir de si mesma, mas para se encontrar, não para se renunciar, mas para se afirmar, nesse dia o amor tornar-se-á para ela, como para o homem, fonte de vida e não perigo mortal". (BEAUVOUIR, online, 2016).

violência familiar torna-se invisível aos olhos da sociedade, convertendo-se então a algo natural no seu cotidiano. Esse estudo permitirá compreender os significados e o próprio processo de análise podendo assim contextualizar as suas multifaces e multicausais vivenciadas por mulheres que já vivenciaram a violência doméstica. Visa ainda entender os paradigmas que cerceiam essas vítimas, como o fato da permissividade por todos os abusos psicológicos, físicos e morais que sofrem.

A violência de gênero se apresenta como uma forma mais extensa e se generalizou como uma expressão utilizada para fazer referência aos diversos atos praticados contra mulheres como forma de submetêlas a sofrimento físico, sexual e psicológico, aí incluídas as diversas formas de ameaças, não só no âmbito intrafamiliar, mas também abrangendo a sua participação social em geral, com ênfase para as suas relações de trabalho, caracterizando-se principalmente pela imposição ou pretensão de imposição de uma subordinação e controle de gênero masculino sobre o feminino. A violência de gênero se apresenta, assim, como um 'gênero', do qual as demais, são espécies. (SOUZA, 2007 p.35)

No decorrer do presente estudo, objetivase discutir sobre a criação da Lei 11.340/06, voltando a problematização do termo "violência doméstica", constantemente, usado para se referir a Lei Maria da Penha.

Em um primeiro momento, o foco estará voltado para a criação desta lei, o que motivou tal norma e as atualizações que sofreu, do surgimento à atualidade. Pretende-se também, analisar o impasse da importância social da lei citada e sua eficácia por meio de casos concretos. A seguir, a classificação dos tipos de violência e em que consiste o chamado Ciclo da Violência. Não fugindo ao conteúdo da lei, tratar-se-á das medidas provisórias, apresentando um breve comentário sobre sua aplicação para casais homoafetivos. Por fim, analisar-se-á em quais situações ela pode ser utilizada de forma plena e eficaz.

\section{O RECONHECIMENTO DA VIOLÊNCIA CONTRA A MULHER: COMO SE DEU A EVOLUÇÃO LEGISLATIVA \\ BRASILEIRA}

A prática da violência contra a mulher não é um problema social novo. Tal conduta se desenrola desde os povos antigos e infelizmente a evolução legislativa não se deu da forma que se esperava diante do tempo e do espaço. Contudo, o Brasil tem um grande marco legislativo para o tema: a Lei $\mathrm{n}^{\circ}$ 11.340, de 07 de agosto de 2006. Acredita-se que esta lei é uma forma de buscar e de garantir os direitos quanto á igualdade de gêneros.

Como já se imagina, nosso Brasil passou por um enorme processo evolutivo antes de alcançar a elaboração e a vigência desta lei. O primeiro fato ocorrido sobre o tema se deu em fevereiro de 1984, quando houve a ratificação da Convenção Sobre a Eliminação de Todas as Formas de Discriminação Contra a Mulher. Logo após, em 1988, nossa Constituição Federal consagra a igualdade entre os sexos, nota-se aqui 
que se constitui um princípio constitucional de extrema valia quanto ao tema tratado.

Em 1995 ratifica-se a conhecida Convenção de Belém do Pará, que se fundamenta com a já existente Convenção Interamericana para prevenir e erradicar a Violência Contra a Mulher. Quanto às denúncias, temos que em 2002 passa a existir a possibilidade de serem enviadas individualmente à Organização dos Estados Americanos; isso ocorreu devido ao fato do Brasil assinar o Protocolo Facultativo à Convenção Sobre Todas as Formas de Discriminação Contra a Mulher. Por fim, alcança-se o ápice legislativo da questão: a Lei n 11.340/2006, conhecida por Lei Maria da Penha.

\subsection{Origem da norma: Como e por qual motivo se criou a Lei 11.340}

Segundo o OBSERVE - Observatório Lei Maria da Penha, a norma de $n^{\circ} 11.340 / 06$, tem este nome em homenagem à Maria da Penha Maia Fernandes. Esta mulher cearense foi casada com Marco Antonio Herredia Viveros. Durante 20 anos Maria da Penha lutou para ver seu esposo preso. Isso se deu pelas tentativas de assassinato que ele cometeu contra ela. A primeira tentativa ocorreu em 1983, quando Marco desferiu tiros nas costas de Maria enquanto esta dormia. Depois desta situação, o esposo alegou que foram atacados por assaltantes. O resultado desta conduta: Maria ficou paraplégica.

Meses depois ocorreu a segunda tentativa. Marco empurra Maria da Penha de sua cadeira de rodas e tenta eletrocutá-la no chuveiro. As investigações começaram em junho daquele ano, contudo apenas em setembro do ano seguinte que a denúncia foi apresentada ao Ministério Público Estadual. O primeiro julgamento só ocorreu oito anos depois, em 1981, sendo anulado com o intermédio dos advogados de Marco. Julgado novamente em 1996 e condenado a dez anos de reclusão, Marco conseguiu recorrer. A interferência da Comissão Interamericana de Direitos Humanos, solicitada por ONGs que auxiliaram Maria, conseguiu fazer com que o esposo fosse preso em 2002 e cumprisse pena de dois anos.

Desta maneira, esta lei surge com a função de proteger a mulher, física e psicologicamente, de qualquer agressão. Uma curiosidade sobre esta lei é que ela não é uma Lei Penal. A norma em questão trata-se de uma Lei Multidisciplinar, ligando-se a outros ramos do Direito, como exemplo o Direito Civil e o Direito Previdenciário.

Ao se analisar o código da lei percebe-se que seus propósitos, ou seja, suas finalidades estão explanadas em seu art. $1^{\circ}$, onde temos:

Art. 1o Esta Lei cria mecanismos para coibir e prevenir a violência doméstica e familiar contra a mulher, nos termos do $₫$ $8^{\circ}$ do art. 226 da Constituição Federal, da Convenção sobre a Eliminação de Todas as Formas de Violência contra a Mulher, da Convenção Interamericana para Prevenir, Punir e Erradicar a Violência contra a Mulher e de outros tratados internacionais ratificados pela República Federativa do Brasil; dispõe sobre a criação dos Juizados de Violência Doméstica e Familiar contra a Mulher; e estabelece medidas de assistência e proteção às mulheres em situação de violência doméstica e familiar.

Diante da simples leitura constata-se que a preocupação do legislador foi além da simples criação de mecanismos de prevenção e de órgãos 
responsáveis. A partir do momento que se estabelece medidas de assistência e de proteção às mulheres em situação de violência doméstica e familiar, cria-se uma questão de preocupação com os fatos passados e também com os fatos presentes, não se prendendo a uma visão futurística para se aplicar a lei.

\section{A VIOLÊNCIA}

A legislação penal vigente em nosso país apresenta uma previsão quanto aos elementos, trazendo situações as quais se refere há momentos onde determinados fatores serão vistos como circunstâncias qualificadoras para o delito em questão e ocasiões onde serão constitutivos dos crimes.

Como exemplos para as ocasiões citadas, usaremos o elemento da violência. $\mathrm{Na}$ primeira situação têm-se o artigo 163, parágrafo único, inciso I do Código Penal Brasileiro, onde se lê: "Destruir, inutilizar ou deteriorar coisa alheia: Pena - detenção, de um a seis meses, ou multa. Dano qualificado. Parágrafo único - Se o crime é cometido: I - com violência à pessoa ou grave ameaça".

Vale ressaltar que nesta situação, a qualificadora só será aplicada se da violência resulta-se lesão corporal grave ou em morte da vítima. Continuando com o mesmo raciocínio, temos a situação onde o elemento constitui o crime exposta na própria lei $\mathrm{n}^{\circ}$ 11.340/06. Mas em tese, em quê consiste a violência?

Mirabette (1999, p.945) conceitua violência, em uma visão de sentido estrito como o "desenvolvimento de força física para vencer resistência, real ou suposta”. Além deste conceito, fazendo uso da mesma visão, o doutrinador apresenta a violência como sendo o "emprego de força material cometida contra outra pessoa".

Analisando um sentido próprio deste elemento, nota-se a sua existência quando o agente faz emprego de meios físicos sobre a pessoa da vítima, não sendo necessário que haja morte, danos anatômicos ou ofensa à saúde, bastando que tenham ocorrido as chamadas vias de fato.

Por este termo entende-se por "todo ato agressivo material que não cause à integridade corporal da vítima dano capaz de ser definido como lesão corporal” (MIRABETTE, 2000, p.103)

\subsection{As formas de violência}

Não fugindo dos costumes de classificar os elementos, a violência também perpassa por esta fase. Em seu artigo $7^{\circ}$, a Lei Maria da Penha apresenta de forma explícita a formas de violência contra a mulher. Diante do código da lei, temos o seguinte texto:

Art. $7^{\circ}$ São formas de violência doméstica e familiar contra a mulher, entre outras:

I - a violência física, entendida como qualquer conduta que ofenda sua integridade ou saúde corporal;

II - a violência psicológica, entendida como qualquer conduta que lhe cause dano emocional e diminuição da autoestima ou que lhe prejudique e perturbe o pleno desenvolvimento ou que vise degradar ou controlar suas ações, comportamentos, crenças e decisões, mediante ameaça, constrangimento, humilhação, manipulação, isolamento, vigilância constante, perseguição contumaz, insulto, chantagem, ridicularização, exploração e limitação do 
direito de ir e vir ou qualquer outro meio que lhe cause prejuízo à saúde psicológica e à autodeterminação;

III - a violência sexual, entendida como qualquer conduta que a constranja a presenciar, a manter ou a participar de relação sexual não desejada, mediante intimidação, ameaça, coação ou uso da força; que a induza a comercializar ou a utilizar, de qualquer modo, a sua sexualidade, que a impeça de usar qualquer método contraceptivo ou que a force ao matrimônio, à gravidez, ao aborto ou à prostituição, mediante coação, chantagem, suborno ou manipulação; ou que limite ou anule o exercício de seus direitos sexuais e reprodutivos;

IV - a violência patrimonial, entendida como qualquer conduta que configure retenção, subtração, destruição parcial ou total de seus objetos, instrumentos de trabalho, documentos pessoais, bens, valores e direitos ou recursos econômicos, incluindo os destinados a satisfazer suas necessidades;

$\mathrm{V}$ - a violência moral, entendida como qualquer conduta que configure calúnia, difamação ou injúria.

Diante de tantas classificações o Conselho Nacional de Justiça (CNJ) apresenta conceitos para cada tipo. Dentre elas, vê-se que a mais geral, ou seja, considerada ampla, é a violência física. Esta classificação baseia-se em toda e qualquer ação ou omissão que de alguma forma coloque em perigo ou acabe causando danos à integridade física de uma pessoa. Aplicando este conceito na lei $n^{\circ}$ 11.340, concluí-se que o sujeito passivo é a pessoa do sexo feminino.

Não desprezando as demais classificações e seguindo a mesma linha de raciocínio, acredita-se que a principal seria a violência de gênero, conceituada como: "violência sofrida pelo fato de se ser mulher, sem distinção de raça, classe social, religião, idade ou qualquer outra condição, produto de um sistema social que subordina o sexo feminino" (CNJ, 20016, online).

A partir deste conceito temos um dos mais discutidos motivos que levam a agressão. Contudo, a Lei Maria da Penha não trata da violência de gênero de forma ampla, fugindo da generalidade ao especificar a violência contra a mulher e restringir as formas entre a doméstica e a familiar.

Segundo o CNJ (2016, online), a violência contra a mulher consiste em "qualquer conduta de discriminação, agressão ou coerção, ocasionada pelo simples fato de a vítima ser mulher" que apresente como resultado "morte, constrangimento, limitação, sofrimento físico, sexual, moral, psicológico, social, político ou econômico ou perda patrimonial". Quanto aos locais onde pode ocorrer, seu conceito não restringe, possibilitando que ocorra em locais públicos ou privados.

Em seu conceito de violência doméstica, o CNJ (2016, online) apresenta uma visão simples e de fácil entendimento: "ocorre em casa, no ambiente doméstico, ou em uma relação de familiaridade, afetividade ou coabitação". Nota-se que existe relação entre essa forma de violência com a violência familiar, sendo esta conceituada como aquela que: "acontece dentro da família, nas relações entre os membros da comunidade familiar, formada por vínculos de parentesco natural ou civil, por afinidade ou afetividade". Neste diapasão temos uma nova classificação: a violência intrafamiliar. $O$ conceito apresentado para essa nova visão diz o seguinte segundo CNJ (2016, online): “da família que viva com a vítima. As agressões domésticas incluem: abuso físico, sexual e psicológico, a negligência e o abandono". 
Mirabette (2000) apresenta que a violência pode ter por objeto não só as pessoas, como também as coisas (res). Percebe-se perfeitamente por esse entendimento no inciso IV citado anteriormente, que se refere à violência patrimonial. O CNJ entende este conceito de forma curta, facilitando o entendimento perante o código. Em suma, o Conselho (2016, online) diz que violência patrimonial é todo "ato de violência que implique dano, perda, subtração, destruição ou retenção de objetos, documentos pessoais, bens e valores".

A violência psicológica consiste em:

Ação ou omissão destinada a degradar ou controlar as ações, comportamentos, crenças e decisões de outra pessoa por meio de intimidação, manipulação, ameaça direta ou indireta, humilhação, isolamento ou qualquer outra conduta que implique prejuízo à saúde psicológica, à autodeterminação ou ao desenvolvimento pessoal. (CNJ, 20016, online).

Outra classificação é a violência sexual que

o CNJ (2016, online) define como:

Ação que obriga uma pessoa a manter contato sexual, físico ou verbal, ou a participar de outras relações sexuais com uso da força, intimidação, coerção, chantagem, suborno, manipulação, ameaça ou qualquer outro mecanismo que anule ou limite a vontade pessoal. Considera-se como violência sexual também o fato de o agressor obrigar a vítima a realizar alguns desses atos com terceiros.

Os crimes contra a honra também são defendidos nesta lei. Entende-se por esta modalidade os crimes de calúnia, difamação e injúria contidos no Código Penal Brasileiro. A objetividade jurídica destes delitos é a tutela a honra objetiva, preservando a reputação dos indivíduos perante os grupos sociais.
O art. 138 do Código Penal apresenta que: "Caluniar alguém, imputando-lhe falsamente fato definido como crime". Ou seja, na calúnia o agente pressupõe a atribuição da execução de algum ato criminoso a alguém. Logo a seguir, em seu artigo 139 temos a conduta da difamação, onde se lê: "Difamar alguém, imputando-lhe fato ofensivo à sua reputação", desta forma, o agente atribui a alguém algum fato concreto e determinado que seja visto negativamente pelos outros. Por fim, na injúria, temos o seguinte no artigo 140: “Injuriar alguém, ofendendo-lhe a dignidade ou o decoro". Neste ponto existe a maior diferença entre estas condutas. $\mathrm{Na}$ injúria o agente não narra nenhum tipo de fato, mas atribui qualidade negativa a alguém, ou seja, um xingamento ou insulto.

Relacionando essas condutas com as formas de violência entende-se que sua prática caracteriza a violência moral, pois objetiva a negativação da honra ou da reputação. A lei 11.340 também defende a mulher desta forma de ridicularização, sendo apresentada no inciso $\mathrm{V}$ do artigo $7^{\circ}$ citado anteriormente.

É importante frisar que essas formas de violência podem ser praticadas isoladamente ou em conjunto, ou seja, existe a possibilidade de que o agressor utilize mais de uma forma de violência contra a ofendida.

\subsection{O ciclo da violência}

Normalmente, a violência interpessoal não acontece constantemente e nem ao acaso. As agressões seguem um padrão, infligindo um ciclo repetitivo. Baseado na cartilha Viver sem Violência é Direito de Toda Mulher disponibilizada pela 
Secretaria de Políticas para as Mulheres em Abril de 2015. Entende-se que este ciclo possui três fases distintas que se inicia com a criação da tensão, que transitará para o ato violento em si sendo seguido por uma fase tranquila e amorosa.

\subsubsection{A criação da tensão: a primeira fase do ciclo}

A cartilha Viver sem Violência é Direito de Toda Mulher (2015, online) apresenta que:

Fase inicial é marcada pela tensão, que tende a aumentar de forma gradual em um período de tempo que varia de dias até anos. Com esse fato, a relação passa a ser rodeada de agressões e humilhações, surgindo assim, comportamentos negativos.

A mudança de comportamento do parceiro é notável e a mulher se atenta a essa alteração. De forma progressiva, o parceiro se torna um indivíduo raivoso e principalmente agitado. Neste cenário, a mulher já se encontra completamente preocupada e apresenta precaução nas situações que envolvem o parceiro. Contudo, a ofendida nega qualquer forma de abuso.

Em casa tudo deve ocorrer bem e a mulher se esforça para que realmente ocorra. Os filhos apresentam um bom comportamento, a casa está sempre bem arrumada e as refeições são servidas no horário rotineiro, sem faltas. E qual o motivo disso acontecer tão perfeitamente? Simples: qualquer incidente acarretará a violência.

As situações de violência que ocorrem passam por enormes devaneios da mulher ao tentar justificar as agressões. Segundo a cartilha Viver sem Violência é Direito de Toda Mulher (online, 2015) "quanto ao homem, este teme que sua companheira o abandone, pois sabe que seu comportamento é totalmente reprovável”. A mulher se retrai e se isola; o medo de novas agressões faz com que ela não queira provocá-lo. As relações entre o casal se encontram cobertas de tensão, se tornando insuportáveis. Toda essa situação, acompanhada de seus fatores, nos dirige a fase dois.

\subsection{2. $\mathrm{O}$ ato de violência: a segunda fase do ciclo}

Segundo a cartilha Viver sem Violência é Direito de Toda Mulher (online, 2015), "compreende-se aqui a fase mais curta do ciclo, durando entre duas a quarenta e oito horas. Normalmente, a violência física é acompanhada da violência verbal".

Os danos físicos sofridos pela mulher são sérios e ela consegue se recordar de cada detalhe, diferente do agressor, que afirma não se lembrar dos fatos. Diante dos danos que sofre, a mulher tenta negar a seriedade da situação, buscando acalmar o agressor. Em muitas situações a mulher, ao pressentir que esta fase se aproxima, age de maneira provocativa para que a agressão ocorra logo. Muitos defendem que isso ocorre devido à raiva ou a ansiedade e até mesmo por não suportar mais o medo. Contudo, a cartilha Viver sem Violência é Direito de Toda Mulher acredita que muito se discute sobre este comportamento se justificar pelo fato de que esta fase é curta e que, em seguida, virá uma fase mais tranquila e mais cômoda: a fase da lua de mel.

2.2.3. Lua de mel: a terceira fase do ciclo Tranquilidade e amor 
Esta é a fase do arrependimento. O agressor se arrepende de seu comportamento e, a partir daqui, começa a se comportar de forma humilde e amorosa, sempre procurando se desculpar. Suas atitudes que buscam o perdão variam desde pedidos de desculpas acompanhados por presentes até promessas de que tudo não voltará a acontecer. A cartilha Viver sem Violência é Direito de Toda Mulher (online, 2015) acredita que todo este cenário fortifica na mulher a esperança de que seu companheiro está em fase de mudanças e isso faz com que ela persista em manter o matrimônio.

Por muitas vezes, a fase três não é acompanhada de comportamentos afetivos, repleta de amor e paixão. Podem ocorrer situações onde este momento se mostre apenas ausente de violência e agressões. Assim, o agressor se apresenta manipulável e acredita que consegue se controlar para não mais repetir o fato ocorrido. A mulher se mostra tentada a acreditar em seu parceiro e as lembranças felizes do começo do relacionamento a instigam a tentar novamente e não romper a relação. $O$ agressor se mostra cabisbaixo e carente, o que faz a mulher acreditar que ele precisa da presença dela, contudo, esta fase levanta a insegurança do homem e isso leva o casal novamente à fase de tensão, retornando a fase um.

A partir de então, a cartilha Viver sem Violência é Direito de Toda Mulher (2015, online) apresenta que o ciclo começa novamente. Percebese de forma clara e sucinta que estas situações caracterizam um ciclo vicioso e prejudicial as relações interpessoais.

\section{A MEDIDA PRO'TETIVA}

\subsection{Conceito}

O direito penal tem como objetivo a tipificação das condutas sociais, com a principal finalidade de garantir à paz social a segurança, o bem-estar dos cidadãos, visando à integridade física, psicológica e principalmente patrimonial. Desta forma desde os seus primórdios o direito está presente para reprimir a violência perante a sociedade.

Podemos compreender por medidas protetivas as medidas que visam garantir que a mulher possa agir livremente ao optar por buscar a proteção estatal e, em especial, a jurisdicional, contra o seu suposto agressor. E para que haja a concessão dessas medidas, é necessário a constatação da prática de conduta que caracterize violência contra a mulher, desenvolvida no âmbito das relações domésticas ou familiares dos envolvidos (SOUZA, 2006, p.04).

Somente com a constatação da prática da conduta onde se verifique a existência de algum tipo das violências já citadas é que essa proteção será concedida.

As classificações das medidas protetivas de urgência baseiam-se naquelas que obrigam o agressor, presentes no artigo 22 da lei $n^{\circ}$ $11.340 / 06$, e naquelas que visam à proteção da vítima, presentes nos artigos 23 e 24 da mesma lei.

\subsection{As medidas protetivas de urgência quanto ao agressor}

Essas medidas são aplicadas a quem pratica a violência doméstica, apresentando obrigações e restrições ao agressor. Presentes no artigo 22 da lei $\mathrm{n}^{\circ} 11.340 / 06$ temos as seguintes medidas:

Art. 22. Constatada a prática de violência doméstica e familiar contra a mulher, nos 
termos desta Lei, o juiz poderá aplicar, de imediato, ao agressor, em conjunto ou separadamente, as seguintes medidas protetivas de urgência, entre outras:

I - suspensão da posse ou restrição do porte de armas, com comunicação ao órgão competente, nos termos da Lei no 10.826, de 22 de dezembro de 2003;

II - afastamento do lar, domicílio ou local de convivência com a ofendida;

III - proibição de determinadas condutas, entre as quais:

a) aproximação da ofendida, de seus familiares e das testemunhas, fixando o limite mínimo de distância entre estes e o agressor;

b) contato com a ofendida, seus familiares e testemunhas por qualquer meio de comunicação;

c) freqüentação de determinados lugares a fim de preservar a integridade física e psicológica da ofendida;

IV - restrição ou suspensão de visitas aos dependentes menores, ouvida a equipe de atendimento multidisciplinar ou serviço similar;

$\mathrm{V}$ - prestação de alimentos provisionais ou provisórios.

$\int 1^{\circ}$ As medidas referidas neste artigo não impedem a aplicação de outras previstas na legislação em vigor, sempre que a segurança da ofendida ou as circunstâncias o exigirem, devendo a providência ser comunicada ao Ministério Público.

$\int 2^{\circ} \mathrm{Na}$ hipótese de aplicação do inciso I, encontrando-se o agressor nas condições mencionadas no caput e incisos do art. $6^{\circ}$ da Lei no 10.826, de 22 de dezembro de 2003, o juiz comunicará ao respectivo órgão, corporação ou instituição as medidas protetivas de urgência concedidas e determinará a restrição do porte de armas, ficando o superior imediato do agressor responsável pelo cumprimento da determinação judicial, sob pena de incorrer nos crimes de prevaricação ou de desobediência, conforme o caso.

$\int 3^{\circ}$ Para garantir a efetividade das medidas protetivas de urgência, poderá o juiz requisitar, a qualquer momento, auxílio da força policial.

$\int 4^{\mathrm{O}}$ Aplica-se às hipóteses previstas neste artigo, no que couber, o disposto no caput e nos $\iint 5^{\circ}$ e $6^{\circ}$ do art. 461 da Lei no 5.869, de 11 de janeiro de 1973 (Código de Processo Civil).
A seguir serão explanados entendimentos sobre cada modalidade.

\subsubsection{Suspensão da posse ou restrição ao porte de armas}

Quanto a essa modalidade de medida protetiva, Dias (2007, p.82) diz que:

Sendo legal a posse e o uso da arma de fogo pelo agressor, denunciando a vitima à autoridade policial a violência $\mathrm{e}$ justificando a necessidade de desarmá-lo, por temer pela própria vida, será instalado expediente a ser remetido ao juízo. Deferido o pedido e excluído o direito do ofensor manter a posse da arma, ou sendo limitado o seu uso, deve-se comunicar a quem procedeu ao registro e concedeu a licença: o Sistema Nacional de Armas (SINARM) e a Polícia Federal. Caso o agressor tenha direito ao uso de arma de fogo, segundo o rol legal, o juiz comunicará ao respectivo órgão, corporação ou instituição que impôs. O superior imediato do agressor fica responsável pelo cumprimento da determinação judicial sob penade incorrer nos crimes de prevaricação ou desobediência. A restrição é valida para evitar tragédia maior. Se o marido agride a esposa, de modo a causar lesão corporal, se possuir arma de fogo, é possível que, no futuro progrida para o homicídio.

Neste sentido, nota-se que o legislador apresenta uma preocupação quanto ao uso de arma de fogo, desejando desarmar o agressor que pratica o ato violento fazendo uso deste objeto. Nos casos onde o agressor possui autorização para possuir a arma o juiz pode suspender sua posse ou restringir seu uso. Nas situações onde a posse é ilegal as autoridades policiais são responsáveis para tomar providencias cabíveis.

\subsubsection{Afastamento do lar, domicílio ou local de convivência com a ofendida}


O inciso II trás a situação onde o agressor será afastado dos lugares onde mantém convivência com a ofendida. Para esta modalidade, pouco se importa que o local seja uma casa, um apartamento, ou até mesmo um quarto de hotel. Contudo, para a concessão desta medida, deve-se existir prática ou risco do agressor cometer algum crime contra a ofendida.

Nas situações onde já se tem histórico de violências, acredita-se que esta modalidade é a mais eficaz. Se o agressor não cumprir a medida, será aplicado o artigo 350 do Código Penal, onde se lê:

Desobediência a decisão judicial sobre perda ou suspensão de direito

Art. 359 - Exercer função, atividade, direito, autoridade ou múnus, de que foi suspenso ou privado por decisão judicial: Pena - detenção, de três meses a dois anos, ou multa.

Nos casos em que o vínculo familiar já foi cessado, será a medida baseada no artigo 150 do Código Penal, que rege sobre a violação de domicílio. Seguindo este entendimento, o autor Porto (2007, p.95) diz que:

Tratando-se de crime de menor potencial ofensivo, conforme determina o art. 69, parágrafo único, primeira parte, da Lei 9.099/95, não se imporá prisão em flagrante, ao autor do fato que assumir o compromisso de comparecer em juízo. Todavia, tal regramento não pode ser aplicado quando a desobediência recair sobre uma medida de proteção à mulher, vitima da violência doméstica ou familiar contra a mulher. Frise-se que esta desobediência a uma imposição judicial de medida protetiva, sempre, de um modo ou outro, caracterizará uma das formas de violência contra a mulher de que trata $\mathrm{O}$ art. $7^{\circ}$ da Lei Maria da Penha.

Desta forma, caberá ao autor que viole a medida a prisão em flagrante.

\subsubsection{Vedação de condutas}

Outra modalidade de medida protetiva é a vedação de condutas. Por meio desta medida existe a possibilidade do agressor ser proibido de realizar certas condutas, desde que isso impossibilite e previna a prática de crimes e proteja as vítimas ofendidas na agressão.

Classificadas como medidas de difícil fiscalização, sua aplicação deve ser bem cogitadas. Nos casos que consistem em ameaças, pode-se solicitar que se conceda a proibição de comunicação por qualquer meio. Com a dificuldade em fiscalizar esta situação Porto (2012, p.96) defende o seguinte entendimento:

Com efeito, na maioria das vezes a ocorrência ou não de crimes, bem como se foi extrapolado o limite entre uma acalorada discussão recíproca e a pratica de ameaça ou ofensas refletidas e sérias é um tema de árdua elucidação. Em primeiro lugar, em razão de à maioria desses delitos - ameaça, crimes contra a honra, perturbação do sossego - ser aplicada penas de detenção ou prisão simples, já não se admite a intercepção das comunicações telefônicas ou telemáticas (art. 2o, III, da Lei 9.296/96). Tem-se, contudo, possam ser requisitados os dados cadastrais dos titulares de telefones utilizados para a pratica de tais infrações, quando a vitima, através de recurso disponível em seu aparelho receptor, tiver identificado a origem das chamadas. Assim, será possível conhecer o autor da ligação, embora não se tenha acesso ao seu conteúdo. Porém, quanto a este, é possível que a vitima grave a conversa por conta própria, utilizando a gravação como prova do delito contra si praticado ameaça, constrangimento ilegal, ofensas pois tal proceder não constitui interceptação telefônica de uma conversa entre terceiros, mas simples, meio de prova de uma dada comunicação efetuada por um dos interlocutores.

\subsubsection{Restrição ou suspensão de visitas}

Porto (2012) indica que essa modalidade deve ser aplicada nos casos em que a violência for 
direcionada aos dependentes menores, especialmente em situações que envolvam maustratos, tentativa de homicídio, tortura ou violência sexual.

Se a situação envolve apenas um menor na prática da violência, a medida pode ser estendida aos demais, devido a existência de risco e a sujeição deles a esse fator. Se a violência envolve a genitora, não se suspende as visitas, mas restringem-se os horários e locais.

As visitas também serão proibidas quando o agressor se encontrar alcoolizado ou em uso de entorpecentes, e também quando frequentar lugares não recomendados.

Nos caos em que a mulher e os filhos são transferidos para abrigos ou casa de parentes a medida se torna mais rígida. No processo não constará o endereço do novo local para que o agressor não saiba o paradeiro. Já quanto às visitas, serão exercidas em locais previamente definidos pela autoridade competente.

\subsubsection{Fixação de alimentos provisionais ou provisórios}

A prestação de alimentos, segundo a Lei Maria da Penha, deve ser fixada pelo Juiz Criminal ou pelo Juizado de Violência Doméstica e Familiar.

Diante das despesas básicas da mulher e dos filhos, caracterizando a dependência econômica, é necessário que se fixe alimentos. Contudo, nos casos onde a mulher possua condições para prover a sua sobrevivência, determina-se a fixação apenas para os filhos.

A definição do valor se dará diante da análise feita pelo juiz das condições do agressor e da ofendida, e também das despesas dos filhos.
Conforme já assinalado ao introduzir o tema das medidas cautelares, o deferimento dos alimentos provisionais pressupõe o ingresso, por parte da ofendida, por si ou em representação de seus dependentes, da competente ação principal no prazo de trinta dias, na Vara de Família ou cível, visto que não compete ao Juiz Criminal e nem mesmo ao Juizado de Violência Doméstica e Familiar Contra a Mulher examinar ação de alimentos que, notoriamente, não tem a violência doméstica por causa de pedir. No seio da ação principal, ou até mesmo em seu exame liminar, poderá o juiz cível ou de família, à vista de melhores elementos, rever os alimentos provisionais fixados pelo juiz criminal, corrigindo eventual excesso ou insuficiência." (PORTO, 2012, p.100).

Os alimentos gravídicos também podem ser concedidos com esta medida. Este tipo de alimento é caracterizado pelas despesas adicionais decorrentes da gravidez, partindo da concepção até o parto. Após o nascimento, convertem-se estes alimentos para pensão alimentícia.

\subsection{Medidas protetivas de urgência a ofendida}

As modalidades de medidas protetivas voltadas à proteção da mulher estão nos artigos 23 e 24 da Lei Maria da Penha, em seu código, temos o seguinte:

Art. 23. Poderá o juiz, quando necessário, sem prejuízo de outras medidas:

I - encaminhar a ofendida e seus dependentes a programa oficial ou comunitário de proteção ou de atendimento;

II - determinar a recondução da ofendida e a de seus dependentes ao respectivo domicílio, após afastamento do agressor; III - determinar o afastamento da ofendida do lar, sem prejuízo dos direitos relativos a bens, guarda dos filhos e alimentos;

IV - determinar a separação de corpos.

Art. 24. Para a proteção patrimonial dos bens da sociedade conjugal ou daqueles de propriedade particular da mulher, o juiz 
poderá determinar, liminarmente, as seguintes medidas, entre outras:

I - restituição de bens indevidamente subtraídos pelo agressor à ofendida;

II - proibição temporária para a celebração de atos e contratos de compra, venda e locação de propriedade em comum, salvo expressa autorização judicial;

III - suspensão das procurações conferidas pela ofendida ao agressor; IV - prestação de caução provisória, mediante depósito judicial, por perdas e danos materiais decorrentes da prática de violência doméstica e familiar contra a ofendida.

Parágrafo único.Deverá o juiz oficiar ao cartório competente para os fins previstos nos incisos II e III deste artigo.

Nota-se claramente que o legislador estabelece uma divisão nas medidas voltadas a ofendida. Em seu artigo 23 trata propriamente da proteção à vítima e em seu artigo 24 tarta dos bens particulares da ofendida e do patrimônio do casal.

\subsubsection{Encaminhamento a programas de proteção e atendimento}

Porto $(2007$, p.100) apresenta o seguinte exemplo:

A Secretaria Municipal de Assistência Social pode ter programas de auxílio habitacional ou alimentar para pessoas necessitadas. A Secretaria de Saúde pode atender a vitima ou seus dependentes se necessitarem algum tratamento médico ou mesmo acompanhamento psicossocial através dos Centros de Atendimento Psicossocial (CAPS).

Percebe-se que a existência de Programas de Proteção e Atendimento é de fundamental importância para a aplicação concreta desta medida. Assim como também se exige que estes programas estejam em perfeito funcionamento, podendo ser criados por meio de ações de grupos de apoio à mulher ou bem como por organizações não governamentais, e principalmente podendo ser criados pelo Estado.
As exigências principais para esses programas baseiam-se na segurança, pois as vítimas que procuram apoio estão em situação de risco. Além disso, exige-se também que exista uma equipe de atendimento multidisciplinar.

\subsubsection{Recondução ao domicílio}

Supõe-se que o afastamento do lar decorre do medo, relacionando às possíveis agressões que a vítima poderia sofrer. Assim, quando não há o recolhimento da vítima em algum Comunitário de Proteção ou em algum Programa Oficial, a recondução será possível.

Nos casos mais difíceis, o transporte da vítima e de seus dependentes é feito para um local seguro, providenciado por condutas a polícia e logo após, requerendo judicialmente o afastamento do agressor. Assim, se o pedido for deferido, a vítima poderá ser reconduzida.

\subsubsection{Afastamento do lar}

Onde se lê, 'determinar' deve-se entender 'autorizar', istoporque o juiz não pode obrigar a vitima a afastar-se do lar; só o agressor pode ser compelido a tanto, caso contrário, estar-se-ia vitimizando-a duplamente. 'Autorizar' significa aqui legitimar o famigerado 'abandono do lar', tido, tradicionalmente, como atitude que atentava contra os deveres matrimoniais. $\mathrm{Na}$ realidade,amulherque abandona o lar, especialmente levando consigo os filhos, tendo depois como provas que o fez por razões de segurança, não pode por isso mesmo ser acusada de haver desentendido obrigações inerentes ao matrimonio, porque o fez em situação de necessidade, sendo-lhe inexigivel conduta diversa, sequer a de que aguardasse uma autorização judicial para sair de casa." (PORTO, 2007, p.101).

Essa hipótese apresenta a situação onde a vítima pode ser afastada, pelo juiz, de seu lar. Não 
haverá prejuízo de direitos relativos aos seus filhos, aos bens e até mesmo aos alimentos.

\subsubsection{Separação de corpos}

Sendo de fácil entendimento, para o deferimento dessa medida, independente de matrimônio ou união estável, é necessária autorização judicial para que se possa afastar o agressor durante o processo de separação ou de dissolução da união estável. A separação de corpos possibilita a suspensão dos deveres de coabitação e convivência.

\subsubsection{Medidas de ordem patrimonial}

As medidas desta classificação encontramse dispostas no artigo 24 da lei $n^{0}$ 11.340. Sua objetividade jurídica é a proteção dos bens do casal e também dos bens particulares da mulher. Souza (2009, p.140) apresenta sobre a concessão desta medida o seguinte entendimento:

$\mathrm{O}$ art. 24 prevê a possibilidade de o juiz do Juizado de Violência Doméstica e Familiar contra a Mulher conceder em favor da vitima, medidas protetivas de natureza eminente patrimonial, voltadas a impedir a pratica comum de o cônjuge, companheiro ou convivente, dilapidar o patrimônio comum ou simular transferências de bens, em prejuízo da vitima. O legislador valeu-se do método empírico e normatizou medidas que já vinham sendo diuturnamente requeridas, principalmente nos juízos de família, mas que, agora, poderão ser aplicadas no mesmo juízo detentos da competência criminal, pois os novos JVDFCM são órgãos detentores de uma competência ampliada, com vistas a possibilitar a almejada proteção integral para a vítima, que agora poderá resolver praticamente todas as questões vinculadas com a agressão doméstica e familiar sofrida, em um único lugar.

Ainda assim, Dias (2007) apresenta que a agressor, tendo este que restituir os bens que tenha subtraído do patrimônio da ofendida, notavelmente, esta conduta caracteriza o furto e diante da Lei Maria da Penha é considerada como violência patrimonial.

A próxima medida apresenta a proibição de celebrar negócios jurídicos. A eficácia desta medida depende da indicação da vítima, ou seja, esta terá que indicar os bens aos quais tem a pretensão de que fiquem interditados da alienação ou da locação em questão do agressor.

Dias (2007) demonstra que em casos onde não existem maneiras discretas de evitar que os envolvidos sejam expostos, será realizada a publicidade da medida protetiva pela imprensa, contudo, apenas quando necessário.

Não vendo o magistrado justificativa suficiente para conceder a restituição reclamada pela vítima, o juiz tem faculdade (art. 22, $\int 1^{\circ}$ ) de determinar tão só o arrolamento dos bens ou o protesto contra alienação de bens, como forma de assegurar a higidez do patrimônio. Desta forme evita a probabilidade de dano irreparável.” (DIAS, 2007, p. 89)

O inciso III trata das situações em que as mulheres confiam imensamente em seus parceiros e os autorizam a conduzir seus negócios, por meio de procurações que lhes conferem plenos poderes. Diante desse cenário, o homem pode usar de má fé e usar as procurações de forma a prejudicar a mulher, fazendo principalmente o desvio de patrimônios.

Nessas situações, poderá o juiz, suspender os poderes das procurações outorgadas pela vítima após a denúncia feita na polícia. Dias (2007, p.90) se manifesta quanto ao assunto de forma clara, dizendo: 


\begin{abstract}
A proibição de celebração de contrato de compra, venda ou locação do patrimônio comum deve ser comunicada ao Cartório de Registro de Imóveis. Já a suspensão da procuração precisa ser informada ao Cartório de Notas. Em todas as hipóteses, para que a decisão possa ser oponível a terceiros, é aconselhável também a comunicação ao Cartório de Registro de Títulos e Documentos.
\end{abstract}

A última medida apresentada no artigo 24 apresenta a caução, ato que consiste em garantir o cumprimento de um dever ou obrigação, desta forma garantirá o pagamento de indenização a vítima. A caução colocará a disposição do juízo os bens ou um fiador que irá assegurar a sua finalidade.

Sobre a caução, Dias (2007, p.89) apresenta:

Todas estas são medidas com natureza extrapenal, que podem ser formuladas perante a autoridade policial quando do registro da ocorrência. Desencadeiam oprocedimento de medida protetiva de urgência a ser enviado a juízo (art.12, III). Essas mesmas pretensões podem ser veiculadas por meio das ações cautelares de sequestro, busca e apreensão, arrolamento de bens, ou mediante outras medidas provisionais. Ainda que se tratem de ações cíveis, como a causa de pedir é a ocorrência de violência doméstica, devem ser propostas perante o JVDFM. Nas comarcas em que esses juizados não estiverem instalados essas ações devem ser propostas pela vitima no juízo cível ou de família e não na Vara Criminal.

\subsection{Como pedir as medidas protetivas de urgência?}

A solicitação da medida protetiva de urgência é feita na delegacia, preferencialmente na Delegacia da Mulher. A ofendida deve-se dirigir ate a delegacia e relatar a agressão que sofreu. Com isso, deve solicitar que no boletim de ocorrência seja registrado o pedido de concessão das medidas protetivas necessárias, sendo estas de acordo com a situação.

O juiz terá o prazo de quarenta e oito horas para apreciar o pedido, sendo este remetido pelo delegado. Neste momento não se exige o acompanhamento de advogado. Também existe a possibilidade de se solicitar ao Ministério Público, por meio de petição. Esta modalidade é recomendada nos casos de maior urgência.

\subsection{Aplicação da Lei Maria da Penha para homens em casais homoafetivos}

A Lei Maria da Penha tem sua aplicação em casos onde o motivo da violência se dá por razões de gênero. Intencionando a prevenção, a punição e a erradicação da violência doméstica e familiar contra a mulher, em virtude do gênero e do princípio de igualdade entre os gêneros, é totalmente aceitável e necessária a aplicação da lei nos casos de crimes praticados contra homens nas relações domésticas.

A caracterização da violência doméstica se dá pela existência de alguma forma de relação familiar ou a existência de afetividade entre os envolvidos, necessitando da vulnerabilidade de uma parte em relação à outra.

Com o reconhecimento da união entre pessoas do mesmo sexo, tem-se a confirmação de que a devida lei também se aplica aos casais homossexuais.

\subsection{A eficácia da medida protetiva}

Atualmente o Brasil enfrenta os mais diversos problemas sociais, vindo ao nosso tema, temos desde mulheres que sofrem discriminação até mulheres que são violentadas. Nosso país 
possui altas estatísticas nestas questões, segundo o Mapa Da Violência o estado com maior índice de agressões em 2015 foi o Mato Grosso do Sul, seguido pelo destaque do Acre, da Roraima, do Tocantins e de Minas Gerais.

Um estudo da Universidade Federal de Minas Gerais (UFMG), apresentado na primeira audiência pública da Comissão, aponta que a cada quatro minutos uma mulher é agredida pela pessoa com a qual ela se relaciona. Segundo a CPMI do Congresso Nacional, cerca de quatro mil mulheres são assassinadas por ano no Brasil. Em Minas, de acordo com informações obtidas pela Comissão junto ao Ministério da Justiça, quatro mulheres são mortas a cada grupo de $100 \mathrm{mil}$ habitantes (MAPA DA VIOLÊNCIA, 2016, online)

Independentemente destes números altos, sabe-se que grande parte dos casos não são denunciados, deixando os agressores impunes. Acredita-se que esta é uma das principais causas para a ineficácia das medidas protetivas, a partir do momento em que a mulher violentada não denuncia seu agressor temos a transformação de um cenário inalcançável pela lei.

Uma das grandes falhas notáveis na Lei 11.340 que é muito usada para justificar a ineficácia de suas medidas é a impossibilidade de se fiscalizar a aplicação de cada medida a cada caso. Isso faz com que exista uma presunção de efetivo cumprimento da medida sancionada, contudo, não existe nenhuma garantia de que ela realmente está sendo cumprida e respeitada.

A pesquisa do Data Senado revelou as diferentes razões que impedem a mulher de recorrer à Lei para enfrentar seus agressores. A principal delas é o "medo do agressor", na percepção de $78 \%$ das entrevistadas em pergunta de múltipla escolha. $\mathrm{O}$ dado é revelador porque o medo se sobressai expressivamente em relação às demais razões. As outras opções - "vergonha", "não garantir o próprio sustento" e "punição branda" atingiram percentuais abaixo de 10\%. Outros motivos foram citados por 16\% das mulheres. A análise desses dados não deixa dúvida de que o medo é o principal obstáculo na luta contra a violência doméstica e familiar. (JORNAL DO SENADO, 2009, online).

Nota-se que mesmo tendo uma legislação específica para essa situação, muitas mulheres ainda sofrem com as mais diversas formas de agressão.

\section{CONCLUSÃO}

O presente trabalho teve como pretensão a análise da Lei $\mathrm{n}^{\circ} 11.340$, popularmente conhecida por Lei Maria da Penha; apresentando os motivos de sua origem e em que consistem as formas de violência que ela apresenta. Além de também apresentar as medidas protetivas que a referida lei trás como solução as agressões denunciadas.

Nota-se que o Brasil é um país que vive em constante evolução jurídica, o que nos faz questionar sobre a eficácia de suas normas. Desta maneira, buscou-se apresentar os principais fatores que influenciam na plena realização das medidas protetivas sancionadas, buscando entender e justificar as críticas sociais que a norma recebe. A garantia de que a medida sancionada é cumprida não existe de fato, o que se considera por ser o principal fator influenciador de sua ineficácia.

Assim como nas civilizações antigas, ainda existe atualmente a imagem de a mulher se configurar como um ser que deve subordinação aos demais, principalmente ao indivíduo do sexo masculino. Isso faz com que a ideia errônea de que 
agressões físicas, morais e emocionais sejam normais, acompanhadas do medo da vítima, coibindo-a de denunciar. A partir deste ponto, apresenta-se como consideração final não a criação de novas normas sobre o assunto, mas sim, a conscientização da população quanto à igualdade de gêneros e trabalhar uma mudança comportamental dos indivíduos no mesmo sentido, inserindo o ser humano desde sua infância em uma educação igualitária que o ensine e o influencie a respeitar a mulher assim como ela é. Desta forma, a sociedade estará plantando a semente de que as diferenças são presentes em todos os cenários, mas a dignidade humana é o que nos faz sermos iguais.

\section{REFERÊNCIAS}

\section{BIBLIOGRÁFICAS}

AMARAL. T.M. A (In)Eficácia Do Estado Na Implementação Das Medidas Protetivas Previstas Na Lei Maria Da Penha, Enquanto Políticas Públicas De Efetivação Dos Direitos De Cidadania. Disponível em:

http://www.unisc.br/portal/images/stories/mes trado/direito/dissertacoes/2012/tatianamar tinsdoamaral.pdf Acesso em: 13 de outubro de 2016.

BEAUVOIR. S. O SEGUNDO SEXO 1. FATOS E MITOS. 4.ed. Disponível em: http://brasilindymedia.org/media/2008/0 1/409660.pdf Acesso em: 10 de outubro de 2016 .

BITENCOURT, Cezar Roberto Tratado de direito penal: parte geral, 1 / Cezar Roberto Bitencourt. - 17. ed. rev., ampl. e atual. De acordo com a Lei n. 12.550, de 2011. - São Paulo: Saraiva, 2012.

BITENCOURT, Cezar Roberto Tratado de direito penal, 4: parte especial: dos crimes contra a dignidade sexual até dos crimes contra a fé pública / Cezar Roberto Bitencourt. - 6. ed. rev. E ampl. - São Paulo : Saraiva, 2012.

BRASIL. Lei 11.340/06. Disponível em: http://www.planalto.gov.br/ccivil_03 /_ato20042006/2006/lei/111340.htm Acesso em: 23 de outubro de 2016

BRUNO. Tamires Negrelli LEI MARIA DA PENHA X INEFICÁCIA DAS MEDIDAS PROTETIVAS. Disponível em:

http://monografias.brasilescola.uol.com.br /direito/lei-maria-penha-x-ineficacia-dasmedidas-protetivas.htm\#sdfootnote38sym. Acesso em: 08 de outubro de 2016.

Conselho Nacional de Justiça: Formas de Violência. Disponível em: http://www.cnj.jus.br/programas-eacoes/lei-maria-da-penha/formas-deviolencia Acesso em: 01 de novembro de 2016

DIAS, Maria Berenice. A LEI MARIA DA PENHA NA JUSTIÇA: a efetividade da Lei 11.340/2006 de combate à violência doméstica e familiar contra a mulher. 2.ed. rev., anual. E ampl. São Paulo: Revista dos Tribunais, 2007.

Instituto Avante Brasil: POR QUE AS MULHERES NÃO DENUNCIAM SEUS AGRESSORES? COM A PALAVRA, A SOCIEDADE. Disponível em: http://institutoavantebrasil.com.br/porque-as-mulheres-nao-denunciam-seusagressores-com-a-palavra-a-sociedade/ acesso em: 10 de novembro de 2016.

JusBrasil: As medidas protetivas patrimoniais na Lei Maria da Penha. Disponível em: http://mgb1637.jusbrasil.com.br/artigos/2 66986890/as-medidas-protetivaspatrimoniais-na-lei-maria-da-penha Acesso em: 15 de outubro de 2016.

MAPA DA VIOLÊNCIA. Disponível em: 
http:/ /www.mapadaviolencia.org.br/pdf2015/Ma paViolencia_2015_mulheres.pdf Acesso em: 29 de outubro de 2016

Migalhas. Lei Maria da Penha: uma evolução histórica. Disponível em: http://www.migalhas.com.br/dePeso/16, MI198444,81042-

Lei+Maria $+\mathrm{da}+$ Penha+uma + evolucao + his torica Acesso: 15 de outubro de 2016.

MIRABETE, J. F. Código Penal Interpretado. São Paulo: Atlas, 1999. Neste sentido a jurisprudência: "A violência física que tipifica o roubo consiste em ação física, que impossibilite, dificulte ou paralise a possibilidade de a vítima evitar a subtração da coisa móvel de que é detentora, possuidora ou proprietária". (TACRIM-SP AC- Rel. Weiss de Andrade - RT 542/374).

MIRABETE, Julio Fabbrini. Manual de direito penal. 16. ed., v. 1. São Paulo: Atlas, 2000.

OBSERVE - Observatório Lei Maria da Penha. Disponível em: http://www.observe.ufba.br/lei_mariadape nha . Acesso em: 22 de setembro de 2016.

PORTO, Pedro Rui da Fontoura. Violência doméstica e familiar contra a mulher: análise crítica e sistêmica. 1. ed. Porto Alegre: Livraria do Advogado, 2007.

PORTO, Pedro Rui da Fontoura. Violência doméstica e familiar contra a mulher: Lei 11.340/06: análise crítica e sistêmica. 2 . ed. rev. e atual. Porto Alegre: Livraria do Advogado Editora, 2012.

SARAPU. P. Mulheres Vitimas de Violência Domestica Tem medo de Denunciar Agressor. EM. COM.BR

GERAIS. Disponivel em:

http://www.em.com.br/app/noticia/gerais/2012 /08/07/interna_gerais,310395/mulheresvitimas-de-violencia-domestica-tem-medo- de-denunciar-agressor.shtml. Acesso em 15 de outubro de 2016

SOS Ação Mulher e Família: Ciclo da Violência. Disponível em: http://www.sosmulherefamilia.org.br/ciclo -de-viol\%C3\%AAncia Acesso em: 29 de outubro de 2016.

SOUZA, João Paulo de Aguiar Sampaio. FONSECA, Tiago Abudda. A aplicação da Lei 9.099/95 nos casos de violência domestica contra a mulher, Boletim do IBCrim n.168, 2006.

SOUZA, Sérgio Ricardo de. COMENTÁRIOS À LEI DE COMBATE À VIOLÊNCIA CONTRA A MULHER. 3. Ed. Curitiba: Juruá, 2007.

SOUZA, Sergio Ricardo de. COMENTÁRIOS A LEI DE COMBATE A VIOLÊNCIA CONTRA A MULHER - LEI MARIA DA PENHA 11.340/06: COMENTÁRIOS ARTIGO POR ARTIGO, ANOTAÇÕES, JURISPRUDÊNCIA E TRATADOS INTERNACIONAIS. 2. ed. Rio de Janeiro: Juruá, 2009.

WESTIN.R. Criada em 2006, Lei Maria da Penha protege mulher de espancamento e assassinato. JORNAL DO SENADO. Disponível em:

http://www12.senado.leg.br/jornal/edicoes/espe ciais/2013/07/04/criada-em-2006-leimaria-da-penha-protege-mulher-deespancamento-e-assassinato Acesso em: 14 de outubro de 2016.

WESTIN.R. Viver sem Violência é Direito de Toda Mulher. Secretaria de Políticas para as Mulheres, 2015. Disponível em: http://www.spm.gov.br/central-deconteudos/publicacoes/publicacoes/2015/1 ivreto-maria-da-penha-2-web-1.pdf Acesso em: 20 de outubro de 2015. 